I do not know if this be similar to that Mr. Grove has seen, but it evidently corresponds with the appearance Mr. Newall describes in your journal for January 27 th. The next mention of inner rainbows is in the Phil. Trans. for 1749 , p. 193, when Mr. Daval, the then secretary of the Royal Society, corroborates, from his own experience, Dr. Langwith's description. Dr. Thos. Young next refers to the phenomenon in order to give his explanation of it in the Phil. Trans. for 1804, and he also twice alludes to it in his published lectures on Natural Philosophy. Further, at p. 374 of his "Optics," Brewster describes supernumerary bows that, at different times, he has seen within the prinary rainbow; and, also, he mentions an analogous appearance observed without the secondary, a fact previously surmised by $\mathrm{Dr}$. Young.* *

An explanation of the phenomenon is first attempted by Dr. Pemberton (Phil. Trans. $\times 722$ ), who classes it with the colours of thin plates, according to the theory of "fits." Dr. Young, in his paper on Physical Objects (Phil. Trans. I804), disputes Dr. Pemberton's explanation, and shows that the appearance is readily explicable by the interference of two pencils of light, regularly reflected from the posterior surface of the drops of rain. The drops must, in this case, be between $\frac{1}{70}$ th and $\frac{1}{80}$ th of an inch in diameter. Evening appears to be the time these supernumerary bows are generally seen, and invariably they are observed beneath the upper part only of the primary bow. Hence, I presume, the phenomenon is similar to the diffraction colours seen in the cloud that is precipitated when the first portions of air are promptiy removed from a receiver.

I have, in conclusion, to thank Mr. Grove for pointing out, in his second letter, that the word "correlation" implies too much when applied to the relationship of colour and music. "Analogy" is certainly far more appropriate to express what is merely a parallelism, and not a necessary or complementary relationship between light and sound.

Woodlands Grove, Isleworth, Jan. 29 W. F. BARRETT

P.S. - Since the foregoing letter was written,--which was sent to your office on the date it bears, - - several contributions on the subject of my "note" have appeared in your journal. I will not now venture to intrude further upon your space, but, with your permission, shall reply to your other correspondents in a subsequent letter.

February 12

W. F. B.

\section{Sensation and Perception}

Having in the Foumal of Mental Science tried to show how Sensation and Intellect are distinguished from each other, allow me to state, in regard to Dr. Bastian's views on this head, that Dr. Lockhart Clarke, after a careful review of what has been written on Sensation, rejects Sir W. Hamilton's statement that "it is manifestly impossible to discriminate, with any rigour, sense from intelligence." "Although, in the lowest animals, there is this apparent identity of sense and intelligence, which seem as it were to be fused into one common state of consciousness, yet when we find them in the course of development, either in the foetus or in the scale of animal life, emerge each in a distinct and different form out of that common or indifferent state, are we to ignore the distinction, and assert with Sir W. Hamilton and others, that sensation is simply a function of the intellect? It might with equal reason be maintained that there is no real difference. between any other two organs of the body, because in the ovum they are developed out of one homogeneous tissue or cummon germinal mass." $\uparrow$ According to Von Baer's law, it seems that while in the lower animals sense and intelligence are fused into one, in the higher they become differentiated, cach having a separate seat. When Dr. Bastian, then, contends, with the metaphysicians, for the identity of sense and intelligence, he seems to be reversing the method of evolution, and going back to the medley out of which welldefined organs with improved functions were evolved. $\mathrm{He}$ would make us believe that as the sense-ganglia become more defined and eliminate the rudiments of intelligence, they assume a lower function than they had before, one not to be distinguished in kind from that of the excito-motor system previously differcntiated. Is this likely? As to the impossibility of discriminating sense from intelligence there are the following facts indicat-

Sir David Brewster, moreover, refers to the occurrence, spoken of by Mr. Newall, of a dark-coloured zone between the primary and secondary bow: a somewhat similar dark fringe is, on i prioni grounds, apparently, predicted by Dr. Young, at p. 369 of his "Lectures on Natural Philosophy, $x 845$ edition.

i Medical Critic and Psychological Journal, vol. ii, p. 574, et seq. ing the contrary. Physiology shows that the external object of the many must be revealed in a seat that is not at the periphery. but such an object is not an idea or notion; therefore, there is a marked distinction between an external object in sense and an idea of one in intellect. A sense-object may be common to two distinct sets of ideas, as when it is now interpreted to be a ghost, now the stump of a tree. A sense-object is antecedent to an ideal object, for the latter only exists as a representation of the tormer. A feeling in sense may cause coughing or sneezing, e.s., in spite of the veto of the intellect. A feeling in sense may be so intensely painful as, for the time, to paralyse intellectual energy. I3ut what about the following argument? What is known at first hand is known as it is, for if you say not as it is ; but as it is not, you imply that it is not known at first hand, but through sumething which does not even represent it, which is absurd. Therefore, as sense and intelligence must be known at first hand, and, as thus known, are distinguishable from each other in many respects, pre-eminently, the one as the sphere of objects at first hand, the other at second hand; the one as pertaining to the organic ego, the other to the non-organic ego-each must be known as it is, not as it is not.

Abergavenny.

\section{Transcendent Space}

W. G. DAVies

In NATURE for January I3 I was permitted, as it were, to speak the prologue to the correspondence on "Kant's View of Space," now happily, if not satisfactorily, closed. I now ask permission to speak the epilogue, in strict reference to the subject of my first letter.

The most interesting period of incubation in Sir William Rowan Hamilton's discovery of Quaternions was October I5, 1843. On that day, as he relates in a letter to a friend, he was walking from his Observatory to Dublin with Lady Hamilton, when, on reaching Brougham Bridge, he "felt the galvanic circuit of thought close; and the sparks which fell from it were the fundamental equations between $i, j, k$; exactly such" as he used them ever since (North British Revieze, September, I866, p. 57). Two days after he wrote a letter to his friend and coadjutor, Mr. J. T. Graves, a brother of the present Bishop of Limerick, giving a most interesting narrative of his transition from Triplets to Quaternions. It is here that $I$ found, after much search and research, the confirmation of a notion which had floated for years in my mind, that Hamilton's speculations had borne a very remarkable relation to Transcendent Space of Four Dimensions. The letter in question is printed in the supplement to vol. $x x v$. (third series) of the L. E. and D. Philosophical Magazine, and of late years has escaped the notice of mathematical students, engrossed, as many are, in the geometrical and physical applications of Quaternions. It seems that after Hamilton had completed his Theory of Conjugate Functions, he endeavoured to obtain an Algebra of Pure Space, and for this purpose employed, after the Germans, the symbol $i$ to express one root of negative unity, and introduced a new symbol, $j$, to express another root of negative unity. Further, he employed an operant, $k$; and with these elements he worked out a theory of Triplets in which $i^{2}=j^{2}=-I$, and $i j=-j i$, while $k$ remained ambiguous. Assuming, at length, that $i j=k$, and $j i=-k$, and leaving it still undecided whethe $k=0$ or not, there dawned on him, as he phrases it, "the notion that we must admit, in some sense, a forsth dimenzsion of Space for the purpose of calculating in triplets."

Now this curiously interesting phase in the generation of Quaternions is an admirable instance of what I mean by affirming Quadridimensional Space to be a mathematical figment springing out of an otherwise uninterpretable formula. Observe, in this case, what was the effect of the completion of the theory. So soon as Hamilton had passed from Triplets to Quaternons, and he liad made his $k$ a third root of negative unity, this transcendent space vanished out of thought. The ghost of a fourth dimension, which had haunted Hamilton's Triplets, was immediately laid; and thenceforth his system was, what he originally sought, an Algebra of Pure Tridimensional Space. The haunting notion, thus banished from Triplets, took refuge in Quinaries and other transcendent algebraical formulisations. To me it is a spurious product of "mental activity," not, even possibly or potentially, a form of mental receptivity, and $a$ fortiori externally denied to experience.

In conclusion, I protest that in denying (for Kant) to Space and Time the title of Forms of Thought, I do not restrict the term Thought to the technical limits of Kant, but use it as synonymous with mental activity in general.

Ilford, Feb. I4 